\title{
Teaching Writing Skills Based on a Genre Approach to L2 Primary School Students: An Action Research
}

\author{
Hyejeong Ahn \\ English as an International Language, School of Languages, Cultures and Linguistics \\ Faculty of Arts, Monash University, Melbourne, VIC 3800, Australia \\ Tel: 61-3-9902-0781Ｅ-mail: hyejeong.ahn@monash.edu
}

Received: September 6, 2011

doi:10.5539/elt.v5n2p2
Accepted: October 11, 2011

Published: February 1, 2012

\begin{abstract}
This article, based on research findings, examines the effect of implementing a genre approach to develop writing competency of Year 5 and 6 L2 primary school students. Using action research, the genre approach was implemented over a 10-week term with two lessons per week in a culturally and linguistically diverse ESL class in a South Australian public metropolitan primary school. Two specific genres, Report and Essay writing, were taught using a three-staged teaching and learning cycle (TLC), based on Vygotsky's notion of scaffolding. Assessment was conducted by comparing students' writing samples, before and after the teaching intervention. The results indicated that the teacher's active scaffolding processes at the early stage of the cycle benefited students by making them aware of the different ways texts are organised for different communicative purposes. In addition, students' confidence level increased and the approach encouraged a positive attitude towards writing.
\end{abstract}

Keywords: Genre approach, Vygotsky, Scaffolding, Writing competency

\section{Introduction}

Globalization has considerably impacted on the use of English throughout the world (Crystal, 2003). Consequently, for an individual to participate actively in the global market, it has become necessary for him/her to develop English writing skills in addition to speaking skills. Writing is often perceived as one of the most challenging aspects of second language ( L2) learning and difficulties in writing different types of texts may come from the fact that writers have to understand the linguistic features of these different text types (Hyland, 2003b). In addition, being able to write cohesively according to the conventions of a specific academic context is even harder for L2 learners to accomplish (Flowerdew, 2002).

One of the most popular ways for L2 students to improve their English is to study in so called English speaking countries for a lengthy period of time. Australia has become a popular destination for these students (Sawir, 2005). In the past two decades, there has been a noticeable increase in the numbers of L2 primary international school students learning English in Australia. When these L2 international primary school students enrol in a mainstream school in Australia, they often encounter difficulties in keeping up with their work, particularly in producing written work. Classroom teachers of newly enrolled L2 students note that these students have grammatical knowledge and developed reading skills and they are motivated to learn English. However, they lack confidence in their writing ability and are often reluctant to participate in writing activities or to submit written assignments.

This project was implemented as a means of helping these L2 students develop their writing skills. It was conducted using action research and its theoretical framework is based on a genre approach, which is arguably one of the most widely accepted writing pedagogies in the Australian school context. This approach follows the principles of the Teaching and Learning Cycle (TLC) that is designed to provide students with explicit and organisational structures for writing for different purposes (Callaghan \& Rothery, 1988).

\section{Theoretical Background}

\subsection{Why Choose a Genre Approach?}

Over the last few decades, there have been numerous L2 writing pedagogies developed to improve students' writing proficiency. In the 1970s and for the most of the 1980s, experts were primarily interested in the process approach which focuses on developing students' linguistic skills through pre-writing activities such as planning, drafting, editing and revising (Badger \& White, 2000; Feez, 2002; Muncie, 2002). In the late 1980s and the 1990s, however, 
theoretical interest in writing instruction shifted to a genre approach that considers writing as a purposeful act and focuses on the analysis of the contextual situation in which writing takes place (Atkinson, 2003; Cheng, 2006, 2007, 2008; Hyland, 2003a, 2003b, 2007; Johns, 2003; Paltridge, 1996, 2000, 2001, 2002, 2007; Swami, 2008). The genre approach was developed in response to the criticism of the limitations of the process approach, which left students to find the recurring text structures for themselves through experimentation and exploration. Feez (2002) argue that the genre approach specifically compensated for this deficit. Paltridge (2007) also claim that many writing conventions would remain opaque for L2 learners unless teachers brought these forms and patterns of language use to their conscious awareness. He (2007) claimed that since drafting, planning and editing were only a part of the entire writing process the process approach was deficient as it did not provide students with clear guidelines in how to construct different kinds of written texts.

Instead the genre approach, particularly at the early learning stage, emphasises on developing the students' awareness of reoccurring textural structures. The teacher's active involvement, through explicit explanation of the contextual dimension, can scaffold for students the distinctive use of the language appropriate to the various genres (Henry \& Roseberry, 1998). When L2 students are left to discover for themselves the complexities of how language works in different genres, they are likely to be thrown back on the discourse conventions of their own cultures (Christie, 1999). Then they may fail to produce texts that are either contextually adequate or educationally valued in the Australian context (Freedman, 1993, 1999; Freedman \& Medways, 1994).

The beneficial aspects of the genre approach have been asserted by a significant number of genre theorists. For example, the genre approach enables students to make sense of the world around them and to become aware of writing as a tool that can be used and manipulated (Kay \& Dudley-Evans, 1998). As Paltridge (2001) claims the genre approach focuses on increasing students' awareness of different ways of organising information in writing, by discussing distinctive features of different purposeful texts. As a result of this process, students systemically acquire a meta-linguistic awareness of the English language, which empowers them to manipulate information and accomplish different purposes through writing.

Furthermore, it is also claimed that the genre approach provides students with the confidence to handle 'real world' writing as it improves students' attitudes and desire toward language learning (Swami, 2008). Many arguments have been put forward in support of genre as an organising principle for the development of L2 learning programs which is why it is arguably the most established and popular writing approach in the Australian school context.

\subsection{An Overview of Different Schools of Genre Pedagogies}

The notion of genre has been interpreted and researched in a variety of ways. Hyon (1996) identifies 'three traditions of genre approaches', separating these into three schools: the English for Specific Purpose(ESP) school, which its central theories relying on Swales' genre analysis (1990); the Sydney school, based on the Systemic Functional Linguistic(SFL) work of Halliday (1984); and the New Rhetoric Group(NRG), influenced by post structuralism in North America. The notion of these three schools was further interpreted by Flowerdew (2002), who separated them into two groups: the linguistic approach (the Sydney school and ESP) and the non linguistic approach (NRG). These two groups take different pedagogical perspectives regarding the way the genre approach should be implemented in the composition classroom (Flowerdew, 2002).

\subsubsection{English for Specific Purposes (ESP)}

Following Swale's work on genre analysis (1990), the notion of the ESP genre approach has often been favoured by researchers who are interested in genre as a tool for teaching discipline-specific writing to L2 learners (Cheng, 2006; Johns, 2003; Kay \& Dudley-Evans, 1998; Swales, 1990). In the ESP tradition, genres are defined as structured communicative events engaged in by specific discourse communities whose members share broad communicative purposes (Paltridge, 2001; Swales, 1990). ESP theorists have shown their commitment to developing research-based language education through the analysis of the constraints of social contexts on language use in academic and professional settings and the ways learners gain control over these. ESP focuses on identifying the key features of genres employed in both academic settings (e.g., research articles, conference abstracts, book reviews, grant proposals, undergraduate essays and $\mathrm{PhD}$ dissertations), and professional settings (e.g., direct mail letters, business faxes and company annual reports).

The identification of recursive features in such genres is believed to clarify their structure for students through consciousness-raising and linguistic awareness tasks. For example, ESP teachers focus on raising students' awareness of the recursive features of the academic essay, such as high lexical density, the frequent use of nominalisation and impersonal statements. It is argued that once students notice the salient features of a genre, they will be able to produce their own examples of the same genre more effectively. Therefore, it is believed that teaching with close attention to recursive textual features will provide learners with a concrete opportunity to 
acquire the conceptual and cultural frameworks of their L2 environment and enhance their chances of communicating successfully in particular communities (Cheng, 2006; Hyland, 2003b, 2007).

\subsubsection{The Sydney School}

The notion of the Sydney school has been successfully applied alongside ESP in the Australian school context (Paltridge, 2001). The Sydney school refers to genres as text types (Hyland, 2007). The classification of genres as text types is reported to be particularly useful to both teachers and students as it provides a means of understanding different features of target genres. The Sydney school genre theorists attempt to provide a linguistic framework for teachers by categorising genres into seven text types (i.e. narrative, recounts, arguments and exposition (see table1), according to broad rhetorical and linguistic patterns. Their focus is on how these seven types of genre can be taught successfully in school settings.

The fundamental principles of text type draw on the notion of Halliday's (1985) systemic functional grammar (SFG). The SFG was developed in response to limitations found in formal grammar instruction in schools that were disconnected from the real use of the language learning (Halliday, 1985; Martin \& Rothery, 1993; Vygotsky, 1978). The SFG focuses on understanding of the ways language is used to make meaning in particular contexts and develops semantically oriented grammars for students to practically use the knowledge (Cope \& Kalantizis, 1993; Martin, 1993; Martin \& Rothery, 1993).

The Sydney school genre approach is implemented extensively in the classroom using the TLC (see figure1) developed by Callaghan and Rothery in 1998, as an instructional tool, particularly in primary and secondary school contexts in Australia. ESP curricula, on the other hand, have been mainly designed for adult students. The TLC comprises of three phases; a modelling phase, a joint negotiation phase and an independent phase. During the modelling phase, the teachers provide direct instructions to students and this interventional role is seen as a crucial part of developing students' conscious awareness of the recursive features of linguistic patterns, ensuring they understand and can reproduce the conventional patterns of the texts in question (Paltridge, 2001). Then, overtime, the teacher's role gradually diminishes as the students become autonomous to be able to express their own meanings through the texts of their choice (Hyland, 2003a, 2007).

The principles of the TLC have been largely influenced by the work of the Russian psychologist Vygotsky and his scaffolding theory (Hyland, 2007). The scaffolding theory promotes the idea that learning occurs most efficiently when learners interact with a more knowledgeable person such as a teacher receiving assistance from him/her, within the Zone of Proximal Development (ZPD). This is the zone where an individual can develop with or without assistance (Vygotsky, 1978).

To summarise, the two groups, ESP and the Sydney school which have been identified as linguistically grounded groups by Flowerdew (2002), are committed to language education, by supplying teachers with a framework which characterises genres in terms of their recursive linguistic patterns. These groups consider that all texts can be described in terms of both the function they serve and their contextual structure. In other words, how component elements are organised to express those functions. Both groups agree that genre knowledge provides students with more equitable access to what is needed to be successful writers. These two groups of genre theorists believe that writing outcomes will be more successful if learners are made aware of the specific features of the target genre through the teacher's explicit explanation and analysis of the target text.

\subsubsection{The New Rhetoric Genre (NRG)}

The scholars who have developed the third genre theory, New Rhetoric Genre (NRG), are generally from North America. They see genre somewhat differently from the ESP and the Sydney school. Their view is influenced by post structuralism and first language composition theories rather than second language acquisition theories, and is based on ethnographic, rather than linguistic perspectives (Hyland, 2007; Hyon, 1996). The NRG theorists focus on unpacking the complex relations between texts and contexts regarding their underpinning ideologies, expressed political beliefs, and cultural and social notions (Freedman, 1999).

Miller (1984), one of most prolific NRG scholars, refers to genre as 'social action' that constitutes society's repeated rhetorical strategies. In other words, the NRG theorists see just as certain social activities arise in a response to previously regulated and repeated situations, in the same way, words are produced in the act of writing in a response to previous words. Freedman $(1994 ; 1993)$ supports this notion by arguing that genre is best understood not so much as a collection of text types, which are defined by their textual regularities, but as a repertoire of typified actions that are produced in response to recurring social contexts.

Although NRG theorists state that clarification of genre knowledge may provide students with a heuristic process to guide their writing, they are skeptical about the pedagogical benefits claimed by the Sydney school and the ESP 
(Coe, 2002; Freadman, 1994; Freedman, 1993, 1999; Freedman \& Medways, 1994). Freedman (1999) argues that the explicit teaching of simplified forms of limited text types can only be useful in raising students' awareness in 'noticing' (1999, p.245) the patterns of linguistic characteristics. In addition, Coe (2002) argues that the implementation of a genre approach as a principle writing pedagogy is dangerous because it has the potential to have the prescriptive and restrictive formulas of, 'how to do' lists. In such a teaching environment, students might expect to be told exactly how to write certain types of texts (Freeman 1994). In addition, since the nature of genre is dynamic, varying from culture to culture and changing, both evolving and decaying continuously, it is nearly impossible to simplify the complex rules of genres and for teachers to acquire accurate knowledge of genres (Bakhtin, Holquist, \& Emerson, 1986).

In sum, NRG theorists see genre as a guiding framework only, and they are skeptical about the pedagogical benefits of the genre approach. They argue that genres in the classroom are mere artifacts for the purpose of study in an inauthentic context and classroom genres are different from those in the real world. Genres are too complex and too varied to be successfully abstracted from their original contexts and taught in an artificial environment such as the classroom (Hyland, 2007). Instead, the NRG theorists argue that genre should be understood within the context of negotiated meanings and the complex and diverse relations of responsive actions in the individually situated contexts (John, 2002).

\subsubsection{Overview of the Three Schools of Genre}

There are considerable differences in the three genre traditions, regarding how the genre approach is implemented and understood in educational settings. Nevertheless, they all agreed that equipping L2 students with the knowledge of genres is critical because it helps them understand their L2 context to effectively participate in their L2 community.

\section{Report on the Project}

As discussed above, there is still much debate on how to implement a genre approach in the educational context. This study practically applies one of the genre approaches, the Sydney school, using action research, to identify its impact and effectiveness of its approach on L2 writing skill development. The study examines whether writing lessons using a genre approach based on the principles of the TLC are connected to students' subsequent writing improvement, after ten weeks of teacher intervention.

\subsection{Educational Context}

This project was conducted in an ESL classroom in a public school located in South Australia. The school has approximately 500 students including ten L2 international students. The school has been actively involved with an international education program for the past six years and has hosted many L2 international students from Asian countries. L2 students are enrolled in this school after completing six months of the new arrival program. This program is designed to help newly arrived L2 students to become familiar with the Australian school environment and provide them with intensive English foundation courses. Upon completion, students are allowed to study in mainstream schools.

Despite spending from six months to one year at schools that offer the new arrival program, when these L2 students study in a mainstream school, they often find it difficult to produce written work that meets the required standard described in South Australian Curriculum Standards and Accountability framework (SACSA framework:Primary years band, 2001). For example, according to the SACSA framework, the students are expected to produce a range of text types and to describe the specific purposes of, as well as the structural and cohesive features commonly found within these text types.

This project was conducted in the ESL classroom, as a means of supporting such a group of L2 students, and the ESL teacher is the researcher of this project who has been teaching ESL students with a genre approach for a number of years. The ESL classroom comprised of seven international students from China and Korea who had completed 6 months of a new arrival program in a designated school and had also spent one term (10 weeks) in a mainstream classroom. At the beginning of the intervention, the quality of their written tasks did not meet the required standard.

One of these students reported that he felt confident about his speaking, listening and reading skills but less confident about his writing ability. A classroom teacher of the student expressed her concerns about his writing problems to the ESL teacher, saying, "He seems to be able to write all day long with many ideas but he doesn't seem to have any structure in his writing." A teacher of a Korean student described her student's problems in this way, "He seems to go off the track whenever he writes something lengthy. He tries to fix the problems but the solution is even more perplexing to me. His sentences mainly start with 'I' only and he overuses his only joining words 'and' 
and 'but'." Both classroom teachers agreed that students would not achieve the required outcomes by the end of the school year unless given additional support.

These students were withdrawn from their classroom to attend an ESL class for a one hour session twice a week for ten weeks. This project aimed to help these students develop their writing skills and raise their awareness of different types of texts to meet the required standard described in the SACSA framework. The project examines whether there was a connection between the writing lessons based on the Sydney school genre approach and the students' subsequent writing improvement, after ten weeks of teaching intervention. In addition, the project attempted to investigate how the genre approach could be implemented effectively in various contextual situations.

\subsection{Lesson Outlines}

The lessons focussed on two specific genres, the report and the essay because these two genres were to be taught in the participant students' classrooms during the following school term. The three phases of the TLC (i.e. modelling, joint negotiation of text and independent construction of text) were used as a guiding framework to organise and sequence the activities in the lessons. They were implemented flexibly to ensure that the tasks and activities the students engaged in were appropriate and relevant (refer to appendix 1 for the detailed outline of the lessons).

\subsubsection{Modelling Phase}

The modelling phase was carried out in the first few lessons devoted to each genre (i.e. report and expository texts). The first few lessons started with oral discussion particularly focusing on developing students' background knowledge, using the notion of SFG registers: field (the social purpose of the text), tenor (the relationship between participants of the event) and mode (the medium of communication) (Thompson, 2004). For example, oral discussion focussed on the social purposes of the target genres (i.e. one is to inform people and the other is to persuade people). Then, the students viewed a number of different resources (e.g. poster, video documentaries) of the same genres and were asked about how people communicate with one another in different ways. For example, in the case of the expository text, the teacher asked a few different questions about ways of delivering an effective argument. The questions included whether, this kind of text uses bias and visual images or not, and whether exaggeration or omission of facts are used to influence the audience. It was interesting to note that while the students already had a few ideas about the genres, they did not know why they need to relate this kind of knowledge to their writing.

After this initial discussion, the focus of the lessons moved to specific language use and some technical terms, associated with the two genres. For example, the students were asked such as "what the words/groups of words 'therefore' and 'as a result' actually do and what they thought the text would sound like if they were not there?." At first, the teacher offered explicit information on the functions of joining words using a few model texts. Then, the students compared and contrasted the characteristics of the language used in each genre. For example, students compared the verbs used in reports with those used in expository texts and also noted the technical vocabulary used in each genre. The students found it quite easy to differentiate reports and expository texts on the basis of which verbs appeared in which. They could clearly see the expository text employed many emotive verbs like, think, feel and know, while these were not found in reports.

\subsubsection{Joint Negotiation Phase}

As the students gained greater understanding of the knowledge of each genre, the lessons moved to the next phase, the joint negotiation phase, which involves a negotiating process during the teacher and the students construct the target texts together. Hammond (1992) claims that in this phase, the teacher's role should diminish gradually enabling the students to progress from the role of an active observer to that of an autonomous learner.

The aim of this phase was for the teacher to work with the students to construct a target text. The teacher at first informed the students the schematic structure specific to the chosen genre and provided them with the examples. During this phase, it was noted that the students began to realise the importance of framing the structure of a text rather than just 'jumping into writing' and thereby showed that they were becoming increasingly aware of the reader's needs, the social purposes and the linguistic features of two specific genres.

Then, the lessons revisited the social and communicative purposes of two specific genres to emphasise effective ways of composing each kind of text and the kind of information needed to produce the target text successfully. The students' contributions during the oral discussion were monitored and it was evident that the students developed a clear understanding of the different social purposes and the need to differentiate the use of language and structure accordingly. For example, during report writing, it was found that they were confident in researching information independently, and knew what information they need to look for. In this case, the topic was 'sea animals' and they used key words that have been previously supplied to help them with their research. After completing their research, 
the students produced a structured report format with four paragraphs each with of a different function (i.e., classification, description of the appearance, its habitat and behaviour and other interesting facts). During the expository text lessons, students were asked to create a 'Yes and No chart' to develop their reasoning skills and to support their ability to elaborate their argument effectively. In this case, the topic was 'smoking should be banned'. It was also noticed that the students were actively involved in building up a rationale to support their argument.

Then, the teacher provided explicit grammar and schematic structure lessons to help the students to convert and reshape their language from the spoken to the written mode. The grammatical features specific to each genre were addressed intensively thorough the process of jointly constructing a text. For example, in the case of an argumentative essay, the activities focused on developing students' understanding of the use of emotive language, high modality, impersonal voice and nominalisation etc. Despite the intensive lessons on grammar, it was observed that the students found it hard to develop a solid understanding of the appropriate use of some grammatical features. For example, the appropriate use of conjunction words such as 'in addition' and 'however' were particularly difficult to achieve. The appropriate use of certain modal verbs (i.e., must vs. should) also challenged the students. They also tend to overuse the newly learned connectives, 'in addition', and 'however' and to employ them merely as replacements of for 'and' and 'but'.

\subsubsection{Independent Construction Phase}

Before reaching this phase, it was sometimes necessary to repeat some activities in the previous phases of the cycle before the students begin independently constructing their own texts. In particular, the teacher repeated lessons that examined grammatical aspects of a text to consolidate students' knowledge, which was noted as the hardest part to achieve. After repeating similar grammar focused activities several times, the students showed a developed understanding of the grammatical points that had presented difficulties.

In this final phase of the TLC, students were given an opportunity to construct an instance of each text type independently. Hammond (1992) claims that in the independent construction phase, the teacher's role consists of being available for consultation with individual students who need specific feedback, instead of providing them with direct support. The students were enthusiastic about the independent writing opportunity. It was gratifying to note the students' growing confidence in their writing ability. Finally, when the students submitted their edited copy to the teacher, they expressed their confidence and satisfaction with their progress.

\subsection{Assessment and Key Data Analysis}

In each phase, the students' progress was continuously assessed either formally or informally and the decision to move on the next phase or to repeat a previous or current lesson again depended on the students' progress. The criteria for assessment (Butt, 2000; Knapp, 2005) used were made explicit and shared with the learners during the joint negotiation phase (Hammond, 1992). Examples of the assessments criteria are presented at the end of this article.

\section{$\underline{\text { Student A's first draft }}$}

When you start smoking, you'll never want to quite. It is really bad for your health. You don't have to smoke. That's what everyone says. And many people are in hospital because of smoke. The smoke makes your lungs decreased. Why do you must smoke? People smoke when they are bored, angry, sad and stressed. The cigar's smoke goes into lung and makes people hard to breathe.

\section{Student A's final copy}

I believe smoking should be banned. There are so many people who smoke everywhere. There are many reasons for this. Firstly, it is an additive habit. Many people say, once you start, it is hard to quick. Secondly many people suffer from sickness related to smoking such as lung cancer.

In order for people to stop smoking, I think that the government should make a strong law against smoking. The current law is not strict enough for the young people not to start in smoking. For example, it is easy for teenagers to buy a package of cigarette from the supermarket and many students use their fake ID cards too.

Therefore, I strongly believe smoking should be discouraged from the young age and it should be banned eventually.

\section{(An artefact from student A)}

Following is a brief analysis of the assessment of student A's final copy. First of all, regarding point 1 and 2 of the criteria in Table 1, the text begins with a clearly stated major proposition and that is, 'I believe smoking should be banned'. The statement of the position is followed by several arguments. The arguments comprise a number of points elaborated by several supporting points. These were 'Firstly it is an additive habit, Secondly many people...lung cancer.' and etc. These points are also organised in a logical way using an appropriate selection of 
language and to begin the paragraphs; that is, the connectives 'firstly' and 'secondly'. The argument concludes with a reiteration of the statement sentence; that is, 'I strongly believe...eventually'.

Regarding the language features, point 3, varied selection of verbs is used. First of all, modality is used in a number of ways through modal auxiliaries (i.e. should) and emotive verbs (i.e. think and believe) to express opinions. The logical relations in the text are clearly established through the connectives (i.e. firstly, secondly and therefore etc...). In addition, there is a movement from personal to impersonal voice which indicates the movement from a subjective opinion to more objective opinion. For example, in the first draft, most of the sentences are simple and personal, while in the final copy, the sentences are more developed beginning with 'government', 'smoking' and 'the current law' etc and a number of passive sentences are also used (i.e. smoking should be discouraged). Finally, there is evidence of employing some abstract forms of language such as nominalization (i.e. sickness) in the final copy. It is evident that the structure and grammatical features of the student A's final copy is a great improvement on the first draft. The final text demonstrates point of view in an organised and logical way and there are adequate uses of elaborated grammatical features.

Through personal observation, as well as the results of the final assessment and comments from the students' classroom teachers, it was obvious that the students for whom this project was conducted had progressed well beyond the initial stage of writing competence. It was also noted that positive changes in their attitude towards writing activities were apparent. One of the students reported that 'It was a lot easier than I thought and it seemed so simple and clear to follow'. The students' progress in their writing competence was satisfactory and most of all, it was exciting to see their confidence in their writing skills growing and to witness their enthusiasm for the approach. The students reflected that they at first felt what the teacher tried to explain to them looked too simple and too much like a 'baby like activity that lower primary students do'. Then they became more aware of the benefits of the explicit explanation and the complexities behind it. They also expressed a desire to learn more about other genres at the end of this project.

The students' comments and the results of this project indicate that this approach can offer L2 students simple and powerful practice in an academic context. The results of this research were particularly successful because the teacher had knowledge of and experience in teaching targeted genres and because of the students, who had already been exposed to an English academic context over a lengthy period of time, already had implicit knowledge of the target genres. Therefore, more research is needed in a various EFL settings where only limited resources are available to gauge how effective the genre approach would be in those settings and further inform educators how to apply the approach effectively in various educational situations.

\section{Discussion}

Despite the wide acceptance of the genre approach using the TLC principles in the Australian school context and the positive outcomes of this small scaled project, a number of researchers (Freedman, 1993; Knapp, 2005; Kress, 1993; Williams \& Colomb, 1993), particularly from the NRG group, have expressed doubts about whether the genre approach can actually help students become better writers. The NRG theorists argue that the tendency for this approach to teach simplified rules of a certain text type will result in students reproducing no more than a set of prescriptive textural types (Freeman, 1993). This is because TLC allows little possibility for the creative manipulation of textual form, hence, possibly reinforcing students to view that the formats presented by the teacher are only rules to follow.

Although the NRG group supports the view that the clarification of genre knowledge could provide students with a useful heuristic process to guide their writing, the danger for students to over-generalise the complex and sophisticated rules of genres needs to be examined before there is any attempt to implement the approach in teaching practice. In order to avoid turning genre instruction into a formulaic type of instruction, precautions need to be taken by L2 teachers. Each lesson should aim to expose students to a variety of academic genres from their readings and class discussion in authentic context. The lessons also should make it clear that students are not expected to replicate a set of mandated textual patterns. Although a lesson may have already been planned by the text book writers, teachers still need to make decisions, adapting the lesson to make it suit different students' needs (Hyon, 1996; Paltridge, 2001). Therefore, it is the teachers who are responsible for translating the principles into practice. In addition, TLC principles should be modified, by moving flexibly forward and backward, depending on students' progress and their needs. This modification may work as a critical factor in giving students a message that the rules can be used in a flexible way to write a text of a particular genre in a contextually adequate yet and unique way.

The NRG theorists also claim that transferring simplified genre rules to students may simply reproduce power inequalities and reinforce dominant discourses, contributing to the maintenance of the powerful dominant culture (Hyland, 2007). Thus, it is also important to reflect whether, when using the genre approach, the student's 
improvement in writing competence should be seen as an entirely positive result. Genres can be composed differently in different cultural academic discourse. Hammond (1992) claims that disciplinary variation in academic writing is not all manifested in the way of the western academic context. For example, it is possible that expository texts are structured in different ways in different linguistic discourse environments. Hence, providing explicit guidelines about how the structures should be organised and what vocabulary should be used may send implicit messages that English language writing principles are superior to the writing principles employed by students' linguistic background. Thus danger should need to be addressed if it is necessary to teach all ESL students to write according to what appeals to be correct in English language context and if this approach empowers English language over their own language (Hammond, 1992). Paltridge (2001) maintains that this is clearly something teachers need to keep in mind when using the genre approach in their classrooms. Therefore, it is essential for teachers to work on developing ways for students to bring their own individual voices into their work within the context of recurring genre patterns.

\section{Conclusion and Suggestions}

This study has shown pedagogical benefits from using genre approach and concerning issues that need to be addressed. Despite the possible limitations of the genre approach, there is little doubt that the work on the genre approach has provided teachers with practical instructional frameworks and activities for presenting genres in the classroom. In addition, this study has shown that the genre approach offers students the power to access to the new culture and to integrate it in their own repertoire of skills and strategies. This study also suggests that it is vital for both educators and learners of ESL to re-examine the educational paradigms and socio-cultural contexts within which a genre approach is to be used should be examined carefully so as to obtain the maximum benefit of the adoption. Thus, further research needs to be conducted on how the genre approach can be applied in L2 teaching without empowering English language culture in a way that it eclipses the student's own culture.

In addition, it is important to note that although much research has discussed how genre can be used as pedagogical tool and its effectiveness as discussed in this study, little emphasis has been placed on the perspectives of the students. Whatever particular pedagogy is used to improve students' writing proficiency, instruction is to reply on students' responses to take effect on their writing performance, thus an understanding is required of how students perceive instruction and how their responses have influenced their writing performances. Therefore, further research on investigating any issues concerning students' responses to instruction based on the genre approach is critical to further development of this approach.

\section{References}

Atkinson, D. (2003). L2 writing in the post-process era: Introduction. Journal of Second Language Writing, 12(1), 3-15. http://dx.doi.org/10.1016/S1060-3743(02)00123-6

Badger, R., \& White, G. (2000). A process genre approach to teaching writing. ELT Journal, 54(2), 153-160. http://dx.doi.org/10.1093/elt/54.2.153

Bakhtin, M., Holquist, M., \& Emerson, C. (1986). Speech genres and other late essays. USA: University of Texas Press.

Butt, D. (2000). Using functional grammar: An explorer's guide (2nd ed. ed.). Sydney: National Centre for English Language Teaching and Research, Macquarie University.

Callaghan, M., \& Rothery, J. (1988). Teaching factual writing: A genre based approach. Marrickville, N.S.W.: DSP Literacy Project, Metropolitan East Region.

Cheng, A. (2006). Understanding learners and learning in ESP genre-based writing instruction. English for Specific Purposes, 25(1), 76-89. http://dx.doi.org/10.1093/elt/54.2.15

Cheng, A. (2007). Simulation-based L2 writing instruction:enhancement through genre analysis. Simulation \& Gaming, 38(1), 67-82. http://dx.doi.org/10.1177/1046878106297879

Cheng, A. (2008). Analyzing genre exemplars in preparation for writing: The case of an L2 graduate student in the ESP genre-based instructional framework of academic literacy. Applied linguistics, 29(1), 50-71, 1. http://dx.doi.org/0.1093/applin/amm021

Christie, F. (1999). Genre theory and ESL teaching: A systemic functional perspective. TESOL Quarterly, 33(4), 759-763. http://www.jstor.org/stable/3587889

Coe, R. (2002). The new rhetoric of genre: Writing political beliefs. In A. M. Johns (Ed.), Genre in the classroom: Multiple perspectives. Mahwah, N.J: L. Erlbaum. pp. 197-210 
Cope, B., \& Kalantizis, M. (Eds.). (1993). The powers of literacy: A genre approach to teaching writing. London: Falmer Press.

Crystal, D. (2003). English as a global language (2nd ed.). Cambridge, UK: Cambridge University Press.

Feez, S. (2002). Heritage and innovation in second language education. In A. M. Johns (Ed.), Genre in the classroom: Multiple perspective. Mahwah, N.J: L. Erlbaum. pp. 43-72

Flowerdew, J. (2002). Genre in the classroom: A linguistic approach. In A. M. Johns (Ed.), Genre in the classroom: Multiple perspective. Mahwah: Routledge.

Freadman, A. (1994). Any one for tennis? In A. Freedman (Ed.), Genre and the new rhetoric. London: Taylor \& Francis. pp. 43-66

Freedman, A. (1993). Show and tell? The role of explicit teaching in the learning of new genres. Research in the Teaching of English, 27(3), 222-251. http://www.jstor.org/stable/40171225

Freedman, A. (1999). Beyond the text: Towards understanding the teaching and learning of genres. TESOL Quarterly, 33(4), 764-767. http://www.jstor.org/stable/3587890

Freedman, A., \& Medways, P. (1994). "Do as I say ": The relationship between teaching and learning new genres. In A. Freedman (Ed.), Genre and the new rhetoric. London: Taylor \& Francis.

Halliday, M. A. K. (1985). An introduction to functional grammar. London: E. Arnold.

Hammond, J. (1992). English for social purposes: A handbook for teachers of adult literacy. Sydney, Australia: National Centre for English Language Teaching and Research.

Henry, A., \& Roseberry, R. L. (1998). An evaluation of a genre-based approach to the teaching of EAP/ESP Writing. TESOL Quarterly, 32(1), 147-156. http://www.jstor.org/stable/3587913

Hyland, K. (2003a). Genre-based pedagogies: A social response to process. Journal of Second Language Writing, 12(1), 17-29. http://dx.doi.org/10.1016/S1060-3743(02)00124-8

Hyland, K. (2003b). Second language writing. Cambridge: Cambridge university press.

Hyland, K. (2007). Genre and second language writing. USA: The university of Michigan press.

Hyon, S. (1996). Genres in three traditions: Implications for ESL. TESOL Quarterly, 30(4), 693-722. http://www.jstor.org/stable/3587930

John, A. (Ed.). (2002). Genre in the classroom: Multiple perspectives. Mahwah, N.J: L. Erlbaum.

Johns, A. (2003). Genre and ESL/EFL composition instruction. In B. Kroll (Ed.), Exploring the dynamics of second language writing. Cambridge: Cambridge University Press. pp. 195-217

Kay, H., \& Dudley-Evans, T. (1998). Genre: What teachers think. ELT Journal, 52(4), 308-314. http://dx.doi.org/10.1093/elt/52.4.308

Knapp, P. (2005). Genre, text, grammar: Technologies for teaching and assessing writing. Sydney: UNSW Press.

Krashen, D. (1987). Second language acquisition theory. Principles and practice in second language acquisition. Hertfordshire: Prentice-Hall International. pp. 9-56

Krashen, D. (1991). The input hypothesis: an update. In J. E. Alatis (Ed.), Linguistics and language pedagogy: The state of the art. Washington DC: Georgetown University Press.

Kress, G. (1993). Genre as social process. In B. Cope (Ed.), The powers of literacy: A genre approach to teaching writing. London: Falmer Press. pp. 22-37

Martin, J. (1993). A contextual theory of language. In B. Cope (Ed.), The powers of literacy: A genre approach to teaching writing. London: Falmer Press. pp. 116-136

Martin, J., \& Rothery, J. (1993). Grammar: Making meaning in writing. In B. Cope (Ed.), The powers of literacy: A genre approach to teaching writing. London: Falmer Press.

Miller, C. R. (1984). Genre as social action. Quarterly Journal of Speech, 70(2), 151-167. http://dx.doi.org/10.1080/00335638409383686

Muncie, J. (2002). Process writing and vocabulary development:comparing Lexical frequency orofiles across drafts. System, 30(2), 225-235. http://dx.doi.org/10.1016/S0346-251X(02)00006-4

Paltridge, B. (1996). Genre, text type, and the language learning classroom. ELT Journal, 50(3), 237-243. http://dx.doi.org/10.1093/elt/50.3.237 
Paltridge, B. (2000). Genre analysis. In B. Paltridge (Ed.), Making sense of discourse analysis. Gold Coast, QLD: Antipodean Educational Enterprises. pp. 105-126

Paltridge, B. (2001). Genre and the language learning classroom. Ann Arbor: University of Michigan Press.

Paltridge, B. (2002). Genre, text type, and the English for Academic Purposes (EAP). In A. M. Johns (Ed.), Genre in the classroom: multiple perspectives. Mahwah, N.J: L. Erlbaum. pp. 73-90

Paltridge, B. (2007). Approaches to Genre in ELT. In J. Cummins, \& C. Davison (Eds.), International Handbook of English Language Teaching, Vol. 15, 931-943. Springer US.

SACSA framework: Primary years band. (2001). Adelaide: Dept. of Education, Training and Employment.

Sawir, E. (2005). Language difficulites of international studints in Australia:The effects of prior learning experience. Internaitonal Education Journal, 6(5), 567-580

Swales, J. (1990). Genre analysis: English in academic and research settings. Cambridge: Cambridge University Press.

Swami, J. A. (2008). Sensitizing ESL learners to genre. TESL-EJ, 13(3), 1-13. http://www.tesl-ej.org/ej47/a9.html

Thompson, G. (2004). Introducing functional grammar (2nd ed.). London: Hodder Education.

Vygotsky, L. (1978). Mind in society and the ZPD. USA: Havard.

Williams, J. M., \& Colomb, G. G. (1993). The case for explicit teaching: Why what you don't know won't help you. Research in the Teaching of English, 27(3), 252-264. http://www.jstor.org/stable/40171226

Table 1. The seven focused genres in Sydney school

\begin{tabular}{|c|c|c|}
\hline Genre & Social purpose & Social Location \\
\hline Recount & $\begin{array}{l}\text { to reconstruct past experiences by retelling events in } \\
\text { original sequence }\end{array}$ & $\begin{array}{l}\text { personal letters, police reports, } \\
\text { insurance claims, incident reports }\end{array}$ \\
\hline Procedure & to show how something is done & $\begin{array}{l}\text { instruction manuals, science, reports, } \\
\text { cookbooks, DIY books }\end{array}$ \\
\hline Narrative & to entertain and instruct via reflection on experience & novels, short stories \\
\hline Report & $\begin{array}{l}\text { to present factual information, usually by classifying } \\
\text { things and then describing their characteristics }\end{array}$ & $\begin{array}{l}\text { brochures, government and business } \\
\text { reports }\end{array}$ \\
\hline Description & to give an account of imagined or factual events & travel brochures, novels, product details \\
\hline Explanation & to give reasons for a state of affairs or a judgment & news reports, textbooks \\
\hline Exposition & to give arguments for why a thesis has been proposed & editorials, essays, commentaries \\
\hline
\end{tabular}


Table 2. Three schools of genre

\begin{tabular}{|c|c|c|c|c|c|}
\hline School & Perspectives & Pedagogy & $\begin{array}{l}\text { Educational } \\
\text { Context }\end{array}$ & Theorists & $\begin{array}{l}\text { Sample } \\
\text { Genres }\end{array}$ \\
\hline ESP & $\begin{array}{l}\text { linguistic } \\
\text { analysis, } \\
\text { discourse } \\
\text { structure, text } \\
\text { features }\end{array}$ & $\begin{array}{l}\text { Vygotsky's view } \\
\text { (scaffolding, ZPD is } \\
\text { represented through: } \\
\text { consciousness } \\
\text { awareness, gradual } \\
\text { approximation, needs } \\
\text { analysis, and rhetorical } \\
\text { approach) }\end{array}$ & $\begin{array}{l}\text { occupational } \\
\text { and academic } \\
\text { settings }\end{array}$ & $\begin{array}{l}\text { J Swales } \\
\text { B Paltridge } \\
\text { A Cheng }\end{array}$ & $\begin{array}{l}\text { e-mail, memo, } \\
\text { business, } \\
\text { letters, } \\
\text { research } \\
\text { articles, } \\
\text { conference } \\
\text { abstracts, book } \\
\text { reviews }\end{array}$ \\
\hline $\begin{array}{l}\text { Sydney } \\
\text { school }\end{array}$ & $\begin{array}{l}\text { linguistic } \\
\text { analysis, } \\
\text { discourse } \\
\text { structure, text } \\
\text { features }\end{array}$ & $\begin{array}{l}\text { Vygotsky's view } \\
\text { (scaffolding, ZPD), } \\
\text { represented in TLC }\end{array}$ & $\begin{array}{l}\text { L1 primary and } \\
\text { secondary } \\
\text { schools }\end{array}$ & $\begin{array}{l}\text { JR Martin } \\
\text { S Feez }\end{array}$ & $\begin{array}{l}\text { narratives, } \\
\text { recounts, } \\
\text { reports, }\end{array}$ \\
\hline NR & $\begin{array}{l}\text { ethnographic } \\
\text { analysis, social } \\
\text { purpose } \\
\text { context, and } \\
\text { responsive } \\
\text { actions }\end{array}$ & $\begin{array}{l}\text { heuristics, general } \\
\text { format }\end{array}$ & $\begin{array}{l}\text { L1 university } \\
\text { composition } \\
\text { (negative views } \\
\text { on transferring } \\
\text { the knowledge } \\
\text { in the writing } \\
\text { classroom) }\end{array}$ & $\begin{array}{l}\text { C Miller } \\
\text { A Freedman }\end{array}$ & $\begin{array}{l}\text { political } \\
\text { briefs, patents }\end{array}$ \\
\hline
\end{tabular}

(Hyland, 2007)

Table 3. Exposition writing assessment list

1. Purpose

1.1 Does the text argue and/or persuade?

2. Structure

2.1 Is the text well organised and logical and does it include a statement of a position, arguments and a conclusion?

$\ldots$

2.4 Does it use a variety of strategies to persuade the audience and reinforce the position?

3. Language features

3.1 Textual language

3.1.1 Does the text use appropriate rhetorical and persuasive devices such as modality?

3.1.3 Does the text have objective statements using nominalisation and impersonal subjects?

3.1.5 Does the text make appropriate use of a variety of connective

3.2 Syntactical language

3.2.5 Is simple and complex punctuation correct?

(For the detailed assessment criteria, refer to appendix 2)

(Adapted from Butt, 2000; Knapp, 2005) 


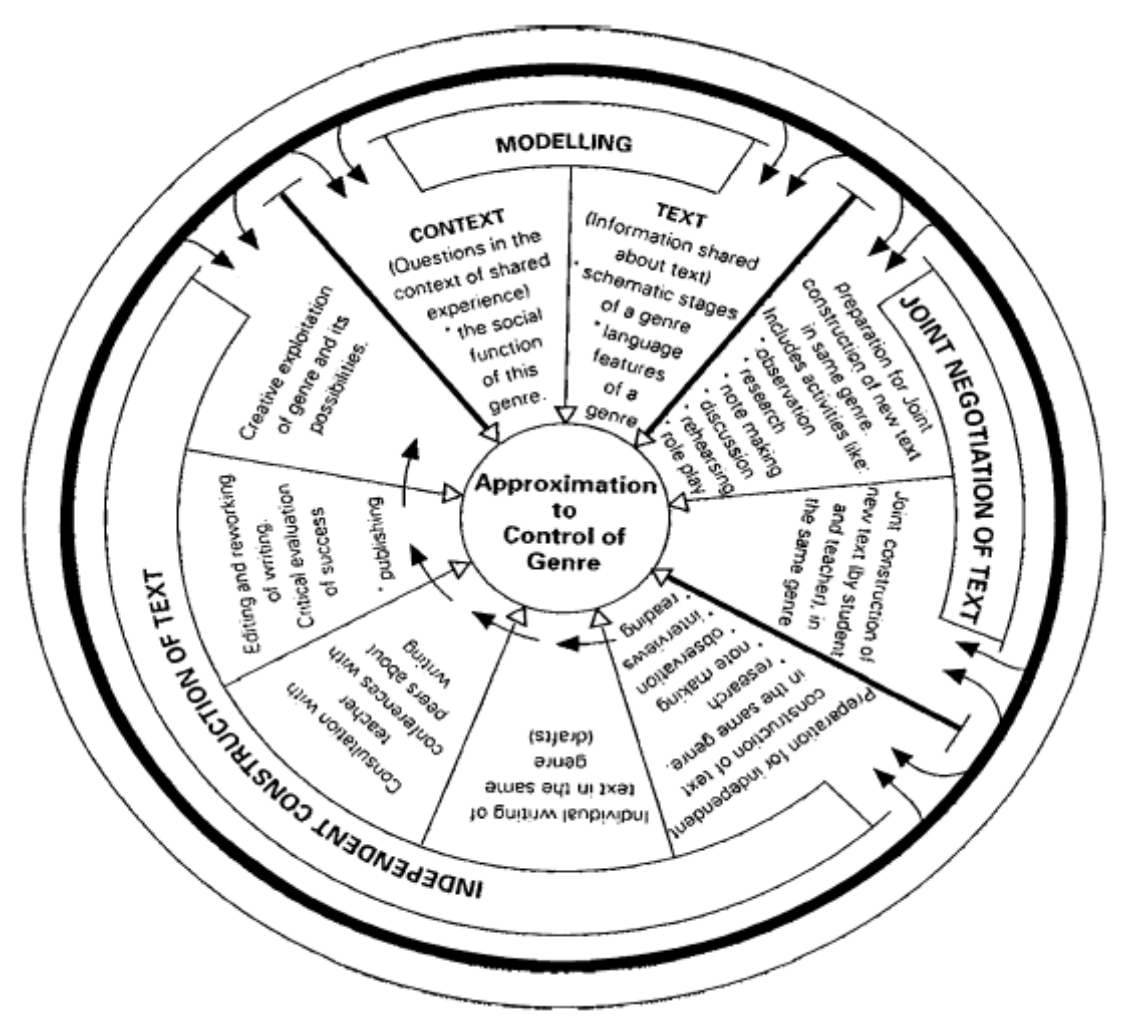

Figure 1. The 'wheel' model of teaching and learning cycle (Callaghan \& Rothery, 1988)

\section{Appendix1: 10 week lesson plan}

\section{Goals:}

To demonstrate purposes for different texts (report and expository text)

To assist the students in learning about different genres

To learn about the structure, language and grammar (using functional grammar), specific to report and expository texts

Time allocated: 2 hours per week over 10 weeks

\section{Part 1}

Genre choice: report

Topic: sea mammals

Time allocated: 5 weeks

Goals:

To develop and consolidate students' knowledge of report

To increase students' knowledge of sea mammals

To discuss new information found about sea mammals (i.e. whales)

To increase students' confidence to write their own reports

To develop students' understanding of grammatical and linguistic features in report

\section{Lesson 1}

- Observe students' pre-knowledge of report, asking students what the purpose of report is, who possible readers are, where it is to be found and what they should write on their report.

- Review some of the characteristics of non-fiction/fiction text.

Lesson 2

- Introduce to 'sea mammals' by examining its classification in general (e.g. What is mammal?). 
- Provide a few resources in different forms (e.g. poster, video clips) and discuss what they find from these visual aids.

- Discuss the format report

Lesson 3

- Give a model of text and discuss its structure and what information needs to be included.

- Discuss technical terms (e.g. topic related terms) and grammatical figures (e.g. tense and impersonal voice etc).

Lesson 4

- Provide the students an opportunity to research their own animal, using key words (habitat, diet, habits, etc).

- The students present the information that they researched based on four sections: classification, description of the appearance, its habitat and behaviour and other interesting facts.

Lesson 5

- Students produce the first draft based on the four sections.

- Discuss what makes one more effective than the other, and highlight both structures and the linguistic features.

- Discuss ways to improve their first drafted writing.

Lesson 6

- Edit and submit their final copy.

- Reflection

\section{Part 2}

Genre choice: expository text

Topic: smoking

Time allocated: 5 weeks

Goal:

To advance or justify an argument or put forward a particular point of view

To develop students' skills to elaborate their argument

To increase students' confidence to write their own expositional text

To develop students' understanding of grammatical and linguistic figures in expository text

Lesson1

- Introduce examples of the expository text and discuss its social purposes (i.e. politicians, essay for university, local councils).

- Explore language features and the structure of a model of expository text and compare them with the ones in report (i.e. use of verbs and connectives).

Lesson 2

- Discuss techniques for persuasion and issues to write about (using a statement sentences with a few supporting sentences).

Lesson 3

- Discuss facts and opinions.

- Practise reasoning skill activities (arguments for and against, using 'yes and no' chart).

- Discuss writers' position.

Lesson 4

- Students begin to research facts to support their argument (i.e. looking for the physical consequences as a result of smoking etc).

- Examine posters, photos, books and videos and discuss what kind of effects these materials have and how persuasive they are, what kind of techniques are used to persuade the audience/readers.

- Students produce a first draft. 
Lesson 5

- Discuss what makes one more effective than the other? and highlight both structure and the linguistic features.

- Discuss ways to improve the first drafted writing.

- Redrafted and revised/peer reviewed.

Lesson 6

- Edit and submit their final copy.

- Reflection

Appendix 2: Writing assessment list

Report assessment list

1. Purpose

1.1 Does the text inform the accurate information of the topic?

2. Structure

2.1 Does the text have series of paragraphs that contain different aspects of the topic?

2.2 Do the paragraphs organise the text coherently?

2.3 Does the text contain structures which build the technical description of a report?

3. Language feature

3.1 Textual language criteria

3.1.1 Does the text use correctly structured simple, compound and complex sentences?

3.1.2 Is the text cohesive through the appropriate use of references?

3.1.3 Is the choice of tense appropriate and consistently maintained?

3.2 Syntactical language

3.2.1 Do the subject and main verb agree?

3.2.2 Are prepositions used appropriately and with some variety?

3.2.3 Are articles used correctly?

3.2.4 Is simple and complex punctuation correct?

3.3 Spelling

3.3.1 Are most high-frequency words spelt correctly?

3.3.2 Are most words with difficult or unusual patterns spelt correctly?

\section{Expository text list}

\section{Purpose}

1.1 Does the text argue and/or persuade?

2. Structure

2.1 Is the text well organised and logical and does it include a statement of a position, arguments and a conclusion?

2.2 Does the text clearly state a problem in the introduction?

2.3 Does the text have a clear statement of position with supporting information?

2.4 Does it use a variety of strategies to persuade the audience and reinforce the position?

2.5 Does it have well-sequenced and cohesive paragraphs?

3. Language features

3.1 Textual language

3.1.1 Does the text use appropriate rhetorical and persuasive devices such as modality?

3.1.2Does the text use a range of simple, compound and complex sentence structures?

3.1.3 Does the text have objective statements using nominalisation and impersonal subjects? 
3.1.4 Is the text cohesive through the appropriate use of pronouns?

3.1.5 Does the text make appropriate use of a variety of connectives?

3.2 Syntactical language

3.2.1 Do the sentences have essential elements such as a main verb and do statements have the subject and main verb in the correct order?

3.2.2 Do the subject and main verb agree?

3.2.3 Are prepositions used appropriately and with some varieties?

3.2.4 Are articles always used correctly?

3.2.5 Is simple and complex punctuation correct?

3.3 Spelling

3.3.1 Are most high-frequency words spelt correctly?

3.3.2 Are most words with difficult or unusual patterns spelt correctly?

(adapted from Butt, 2000; Knapp, 2005) 